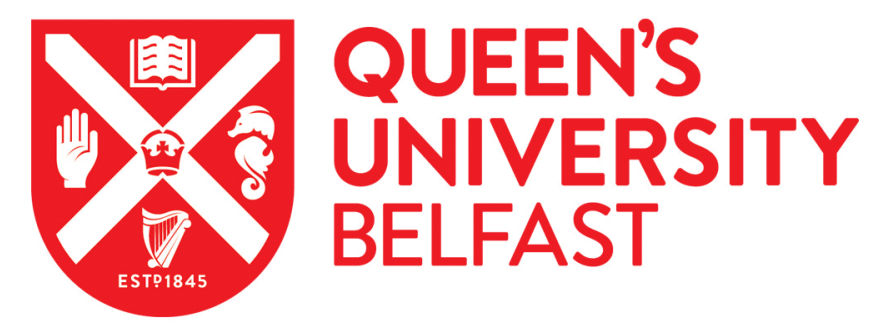

\title{
A sensitive HPLC-UV method for quantifying vancomycin in biological matrices: Application to pharmacokinetic and biodistribution studies in rat plasma, skin and lymph nodes
}

Ramadon, D., Courtenay, A. J., Permana, A. D., Tekko, I. A., McAlister, E., McCrudden, M. T. C., McCarthy, H. O., \& Donnelly, R. (2020). A sensitive HPLC-UV method for quantifying vancomycin in biological matrices: Application to pharmacokinetic and biodistribution studies in rat plasma, skin and lymph nodes. Journal of Pharmaceutical and Biomedical Analysis, 189, [113429]. https://doi.org/10.1016/j.jpba.2020.113429

\section{Published in:}

Journal of Pharmaceutical and Biomedical Analysis

\section{Document Version:}

Peer reviewed version

Queen's University Belfast - Research Portal:

Link to publication record in Queen's University Belfast Research Portal

\section{Publisher rights}

(c) 2020 Elsevier B.V. All rights reserved.

This manuscript is distributed under a Creative Commons Attribution-NonCommercial-NoDerivs License

(https://creativecommons.org/licenses/by-nc-nd/4.0/), which permits distribution and reproduction for non-commercial purposes, provided the author and source are cited.

\section{General rights}

Copyright for the publications made accessible via the Queen's University Belfast Research Portal is retained by the author(s) and / or other copyright owners and it is a condition of accessing these publications that users recognise and abide by the legal requirements associated with these rights.

Take down policy

The Research Portal is Queen's institutional repository that provides access to Queen's research output. Every effort has been made to ensure that content in the Research Portal does not infringe any person's rights, or applicable UK laws. If you discover content in the

Research Portal that you believe breaches copyright or violates any law, please contact openaccess@qub.ac.uk. 
A sensitive HPLC-UV method for quantifying vancomycin in biological matrices: Application to pharmacokinetic and biodistribution studies in rat plasma, skin and lymph nodes

Delly Ramadon ${ }^{a, b}$, Aaron J. Courtenay ${ }^{a, c}$, Andi Dian Permana ${ }^{a, d}$, Ismaiel A. Tekko ${ }^{a, e}$, Emma McAlister ${ }^{\mathrm{a}}$, Maelíosa T.C. McCrudden ${ }^{\mathrm{a}}$, Helen O. McCarthy ${ }^{\mathrm{a}}$, Ryan F. Donnelly ${ }^{\mathbf{a}^{*}}$

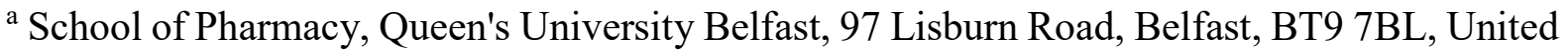
Kingdom

${ }^{\mathrm{b}}$ Faculty of Pharmacy, Universitas Indonesia, Depok, Indonesia

c School of Pharmacy and Pharmaceutical Sciences, Ulster University, Coleraine, United Kingdom

d Department of Pharmaceutics, Faculty of Pharmacy, Hasanuddin University, Makassar, Indonesia

${ }^{\mathrm{e}}$ Department of Pharmaceutics and Pharmaceutical Technology, Faculty of Pharmacy, Aleppo University, Aleppo, Syria

Corresponding author:

Prof Ryan F. Donnelly

School of Pharmacy, Queen's University Belfast, Medical Biology Centre, 97 Lisburn Road, Belfast, BT9 7BL, UK

Email: r.donnelly@qub.ac.uk 


\begin{abstract}
Vancomycin (VCN) is an antibiotic used in the treatment of methicillin-resistant Staphylococcus aureus (MRSA)-derived infections. As it has a relatively narrow therapeutic window, it is imperative to develop a sensitive and reliable analytical method for drug monitoring and pharmacokinetic purposes. In the present study, quick sample preparations and a sensitive high-performance liquid chromatography method using UV detection (HPLC-UV) have been developed and validated. The analytical method for detection and quantification of VCN in rat plasma, skin and lymph node samples was validated based on the Food and Drug Administration (FDA) and European Medicine Agency (EMEA) bioanalytical method validation guidelines. The optimised plasma sample preparation involved a simple protein precipitation step, with extraction recovery of $100.3 \pm 0.92 \%$. VCN in all biological matrices was analysed in a HPLC-UV system $(215 \mathrm{~nm})$ using a Cortecs ${ }^{\circledR} \mathrm{C} 18$ column $(4.6 \times 150 \mathrm{~mm}$, $2.7 \mu \mathrm{m}$ particle size) fitted with a guard cartridge set at $20^{\circ} \mathrm{C}$. Reverse phase HPLC under gradient conditions, with mobile phase consisting of $20 \mathrm{mM}$ phosphate buffer containing $0.5 \%$ $\mathrm{v} / \mathrm{v}$ of triethylamine and a mixture of methanol - acetonitrile $(70: 30, \mathrm{v} / \mathrm{v})$, and runtime of 12 $\mathrm{min} /$ sample was employed. The calibration standards used for plasma ranged between 0.1-50 $\mu \mathrm{g} / \mathrm{ml}$, while in the skin and lymph node matrices, standards ranged between $0.05-50 \mu \mathrm{g} / \mathrm{ml}$ with correlation coefficients $\left(\mathrm{R}^{2}\right)$ of $\geq 0.9995$ for all matrices. The method was selective, sensitive, accurate and precise for detecting and quantifying $\mathrm{VCN}$ in the biological matrices used. The validated method was successfully utilised in the detection of VCN in a pharmacokinetic and organ biodistribution study carried out in rats following oral and IV bolus administration of the drug. This validated bioanalytical method offers a wide range of potential applications in clinical therapeutic drug monitoring, pharmacokinetics and toxicology.
\end{abstract}

\title{
Keywords
}

Vancomycin; HPLC-UV; skin; lymph node; pharmacokinetics 


\section{Introduction}

One of the most effective antibiotics for the treatment of methicillin-resistant Staphylococcus aureus (MRSA)-derived infections is vancomycin (VCN) [1]. This glycopeptide antibiotic is produced by particular strains of Streptomyces orientalis and was first isolated by Dr. E. C. Kornfield, a chemist in the Eli Lilly company, in 1957 [1]. In both aerobic and anaerobic bacteria, VCN acts by blocking the transglycosylase reaction, binding the D-ala-D-ala section of the bacteria cell and hindering bonding between polymer of glycopeptide ( $\mathrm{N}$-acetylmuramic acid - N-acetylglucosamine) [1]. VCN may be used in the treatment of some illness such as endocarditis, osteomyelitis and acute bacterial prostatitis caused by Gram-positive cocci [1]. However, VCN must be administered intravenously for systemic infections because it is poorly absorbed in the gastrointestinal tract [1]. Filippone et al. [2] suggested the minimum level of VCN required to prevent resistance is $10 \mathrm{mg} / \mathrm{L}$ and associated nephrotoxicity may occur when the serum level is more than $15 \mathrm{mg} / \mathrm{ml}$. It is, therefore, imperative to periodically measure VCN concentration in serum to ensure sufficient therapeutic concentration and to prevent toxicity.

Biodistribution studies have shown VCN to be widely distributed into most body organs after administration via intravenous injection or infusion [3], including cerebrospinal fluid (CSF) [4], heart valves [5], lungs [6] and interstitial fluid (ISF) [7]. As a consequence, and for therapeutic drug monitoring purposes, it is important to develop a sensitive and selective method for analysing and quantifying VCN in a range of different biological samples. A variety of different bioanalytical methods have already been employed, including immunologic, biological and chromatographic methods [8]. Chromatographic methods have the potential for greater sensitivity and reproducibility in routine analysis [8]. Thus, chromatographic methods are preferential for analysing VCN in various biological samples. To this end, recent studies have investigated a variety of chromatographic methods, using different detectors, to quantify VCN in biological tissues. Liquid chromatography (LC) coupled with mass spectrometric detection (MS/MS) has been utilised [9]. However, despite its high sensitivity, LC-MS/MS requires highly expensive, sophisticated instrumentation, suffers from limited sample throughput and may give rise to ion suppression [10]. Therefore, other types of LC detectors have also been employed in VCN analysis, such as electrochemical [11], fluorescence [12] and ultraviolet (UV) [13,14]. An exploration of the use of high-performance liquid chromatography (HPLC) with UV detection for the biological analysis of VCN would be advantageous due to 
ease of instrumentation operation; good stability of response and the ability to utilise a wide range of wavelengths in analysis.

Analysis of VCN in the skin interstitial fluid (ISF) has previously performed by Ito et al. [7]. However, it was analysed by using LC-MS/MS, and the data obtained was limited to a $2 \mathrm{~h}$ study. Moreover, the samples were limited to ISF and not the whole skin sample. It is necessary to quantify VCN in all skin compartments (interstitial and intracellular compartments) because the distribution if a drug may vary in these different compartments [15]. VCN has been quantified in a limited number of biological matrices, including plasma and ISF [7] but, to date, no HPLC-UV method for detecting and quantifying VCN in lymph node samples has been published. The intravenous administration of VCN is associated with a drug reaction with eosinophilia and systemic symptoms (DRESS), a rare-life threatening syndrome [16]. Recently, Zafar et al. [16] has reported that one of the DRESS symptoms is the lymphadenopathy, hence, it is necessary to investigate the biodistribution of $\mathrm{VCN}$ in the lymph node. Thus, this present work describes the development of a simple extraction method of VCN from rat plasma, skin and lymph node samples. A sensitive bioanalytical HPLC-UV method validation for quantification of VCN in a range of different biological samples was carried out, based on European Medicine Agency (EMEA) 2011 [17] and Food and Drug Administration (FDA) 2018 [18] guidelines. The validated method was then utilised in an in vivo study to investigate the pharmacokinetic profile of $\mathrm{VCN}$ in rat plasma after oral and intravenous administration over a $48 \mathrm{~h}$ period.

\section{Materials and Methods}

\subsection{Materials}

Methanol, acetonitrile and triethylamine (TEA) were HPLC grade from Sigma-Aldrich (Dorset, UK). Vancomycin hydrochloride (VCN) was purchased from Alfa Aesar (Lancashire, UK). Vancocin $^{\circledR} 500 \mathrm{mg}$ powder (Vancomycin hydrochloride) solution for infusion and oral solution/gavage was obtained from Flynn Pharma Ltd. (Hertfordshire, UK). Sodium dihydrogen phosphate dihydrate was obtained from VWR International (Leuven, Belgium). Orthophosphoric acid was purchased from Amresco (Ohio, USA). Ultrapure water was obtained from a water purification system Elga PURELAB DV 25 (Veolia Water Systems, Ireland). HPLC column Cortecs ${ }^{\circledR} \mathrm{C} 18(4.6 \times 150 \mathrm{~mm}, 2.7 \mu \mathrm{m}$ particle size $)$ were purchased from Waters (Dublin, Ireland). All other chemical reagents were from Sigma-Aldrich (Dorset, UK). All reagents were of analytical grade. 


\subsection{Preparation of VCN calibration standards and quality control solutions in three different}

\section{biological matrices}

VCN stock solution was prepared by dissolving $10 \mathrm{mg}$ of drug in ultrapure water and making up to $10 \mathrm{ml}$ to obtain a concentration of $1 \mathrm{mg} / \mathrm{ml}$. A series of $\mathrm{VCN}$ solutions of different concentrations were then obtained by serially diluting the stock solution in ultrapure water. A plasma calibration standard was prepared by adding $50 \mu \mathrm{l}$ blank rat plasma to $50 \mu \mathrm{l}$ of the relevant VCN standard to achieve serial VCN plasma concentrations in the range $0.1-50 \mu \mathrm{g} / \mathrm{ml}$. Quality control (QC) VCN plasma solutions at low (QCL) $(0.3 \mu \mathrm{g} / \mathrm{ml})$, medium (QCM) (25 $\mu \mathrm{g} / \mathrm{ml})$ and high $(\mathrm{QCH})(40 \mu \mathrm{g} / \mathrm{ml})$ concentrations were prepared using the same method.

Blank skin and lymph node matrices were prepared by adding ultrapure water $(0.45 \mathrm{ml})$ to 50 mg of skin or lymph node. The samples were then disrupted and homogenised using a tissue homogeniser, Tissue Lyser LT (Qiagen, Ltd, Manchester, UK) for $15 \mathrm{~min}$ at $50 \mathrm{~Hz}$ [19]. Following this, samples were centrifuged at $14,000 \times \mathrm{g}$ for $10 \mathrm{~min}$ and the supernatant was collected as the relevant blank matrix solution.

Calibration standards and QC solutions for skin and lymph node samples were obtained by spiking $80 \mu \mathrm{l}$ of the relevant concentration of VCN solution into $80 \mu \mathrm{l}$ of blank matrix (skin or lymph node). The concentration ranges used for skin and lymph node calibration standards were $0.05-50 \mu \mathrm{g} / \mathrm{ml}$, while QC solutions were $0.15,25$ and $40 \mu \mathrm{g} / \mathrm{ml}$, designated as low, medium and high concentrations, respectively.

\subsection{Selection of plasma sample preparation}

The extraction of VCN from rat plasma was tested using four previously published methods, with slight modifications, as listed in Table 1 below. A working solution of $50 \mu \mathrm{g} / \mathrm{ml} \mathrm{VCN}$ was used in these sample preparations and an aliquot ( $50 \mu \mathrm{l})$ of each sample was injected into HPLC with the condition which will be explained in section 2.4. Parameter observed in this selection step was the area obtained from each sample after the extraction process with a specific method as listed below. Then, the area obtained was compared to the area of VCN standard solution (without extraction). 
Table 1. Summary of methods tested for extracting VCN from plasma sample

\begin{tabular}{|c|c|}
\hline Method & Process \\
\hline A & $\begin{array}{l}\left.\text { Spiked plasma (volume) was placed in a centrifugal filtration unit, Amicon }{ }^{(}\right) \text {Ultra (Sigma } \\
\text { Aldrich (Dorset, UK)), with molecular weight cut off of } 30 \mathrm{kD} \text { and centrifuged at } 14,000 \times g \\
\text { for } 10 \text { min, then the supernatant was collected [20]. }\end{array}$ \\
\hline B & $\begin{array}{l}\text { Spiked plasma }(100 \mu \mathrm{l}) \text { was added to } 100 \mu \mathrm{l} \text { methanol in a } 0.5 \mathrm{~mL} \text { microcentrifuge tube, } \\
\text { vortexed for } 30 \mathrm{~s} \text {, then centrifuged at } 14,000 \mathrm{x} g \text { for } 6 \mathrm{~min} \text { at room temperature. The } \\
\text { supernatant was then collected [21]. }\end{array}$ \\
\hline $\mathrm{C}$ & $\begin{array}{l}\text { Spiked plasma }(100 \mu \mathrm{l}) \text { was added to } 100 \mu \mathrm{l} \text { of water in a } 0.5 \mathrm{~mL} \text { centrifuge tube and vortexed } \\
\text { for } 10 \mathrm{~s} \text {. Methanol }(100 \mu \mathrm{l}) \text { was then added to the sample and this was vortexed for } 30 \mathrm{~s} \text {, then } \\
\text { centrifuged at } 14,000 \mathrm{x} g \text { for } 6 \mathrm{~min} \text { at room temperature. The supernatant was then collected } \\
\text { [22]. }\end{array}$ \\
\hline $\mathrm{D}$ & $\begin{array}{l}\text { Spiked plasma }(100 \mu \mathrm{l}) \text { was added to } 100 \mu \mathrm{l} \text { methanol, as explained in method } \mathrm{B} \text {, however } \\
\text { the resulting supernatant was evaporated in a glass culture tube under nitrogen flow at } 20^{\circ} \mathrm{C} \\
\text { for } 20 \mathrm{~min} \text {. The evaporation process was carried out using a Zymark TurboVap }{ }^{\circledR} \mathrm{LV} \\
\text { Evaporator Workstation (Lab Equipment, UK). The residue was then reconstituted with } \\
\text { water }(100 \mu \mathrm{l}) \text { and collected in a microcentrifuge tube, vortexed for } 30 \mathrm{~s} \text {, and centrifuged at } \\
14,000 \mathrm{x} \text { for } 6 \mathrm{~min} \text { at room temperature. The supernatant was then collected [23]. }\end{array}$ \\
\hline
\end{tabular}

\subsection{Chromatographic and instrumentation conditions}

The HPLC analysis of VCN was performed on an Agilent 1200 series system (Agilent Technologies UK Ltd, Stockport, UK) with UV detection at $215 \mathrm{~nm}$. The chromatographic separation was achieved using a Cortecs ${ }^{\circledR} \mathrm{C} 18$ column $(4.6 \times 150 \mathrm{~mm}, 2.7 \mu \mathrm{m}$ particle size $)$, fitted with a guard cartridge set at $20^{\circ} \mathrm{C}$. The mobile phase consisted of solvent A $(20 \mathrm{mM}$ phosphate buffer containing $0.5 \% \mathrm{v} / \mathrm{v}$ TEA, adjusted to $\mathrm{pH} 2.5$ ) and solvent $\mathrm{B}$ (methanol acetonitrile in the ratio, 70:30, v/v). The reverse phase (RP) HPLC gradient conditions and run times employed in this work are provided in Table 2. The total runtime of each sample was 12 min and the injection volume was $50 \mu 1$.

Table 2. Gradient condition utilised for VCN analysis

\begin{tabular}{cccc}
\hline Time (min) & Solvent A (\%) & Solvent B (\%) & Flow rate (ml/min) \\
\hline 0 & 90 & 10 & 0.4 \\
4 & 60 & 40 & 0.4 \\
8 & 90 & 10 & 0.4 \\
12 & 90 & 10 & 0.4 \\
\hline
\end{tabular}




\subsection{Bioanalytical method validation}

A full validation of the bioanalytical method developed in this study was carried out, according to the EMEA 2011 and FDA 2018 bioanalytical method validation guidelines. Parameters validated in this work were: lower limit of quantification (LLOQ), linearity (calibration curve), accuracy, precision, selectivity, carry over, dilution integrity, extraction recovery and stability.

\subsubsection{Selectivity}

The selectivity of the bioanalytical method was investigated by analysing the chromatograms of blank plasma, skin and lymph node matrices from six different sources and the spiked matrices to assess possible interfering compounds in the chromatograms at the relevant VCN retention times.

\subsubsection{Linearity of calibration curve}

Calibration curves were prepared using plasma and working standard solutions. Each calibration curve consisted of one blank sample (plasma without analyte) and 7 non-zero samples (plasma spiked with VCN solutions, including lower limit of quantification (LLOQ) and upper limit of quantification (ULOQ). The concentration ranges used for plasma, skin and lymph samples were $0.1-50 \mu \mathrm{g} / \mathrm{ml}, 0.05-50 \mu \mathrm{g} / \mathrm{ml}$ and $0.05-50 \mu \mathrm{g} / \mathrm{ml}$, respectively. According to EMEA (2011) [17], a new calibration curve must be prepared on each day of analysis and the percentage difference of each actual concentration, compared to the theoretical concentration ( $\%$ diff), should not exceed $\pm 15 \%$, except in the case of the LLOQ where it should not exceed $\pm 20 \%$.

\subsubsection{Lower limit of quantification}

The lower limit of quantification (LLOQ) was determined by diluting the lowest concentration of VCN on the calibration curve two-fold. Each concentration was prepared in five replicates and injected onto HPLC. The \%diff value of each sample and its coefficient of variation (\%CV) was then determined. $\% \mathrm{CV}$ was calculated by dividing the standard deviation (SD) with average concentration measured multiplied by $100 \%$. The LLOQ was the lowest VCN concentration measured which showed the $\%$ diff not less than $-20 \%$ and not more than $+20 \%$, compared to the theoretical value. 


\subsubsection{Carry over}

Carry over is the possibility of a peak appearing in the blank/next injection after the injection of solution at upper limit of quantification (ULOQ) concentration. Carry over was evaluated by injecting standard solution at ULOQ concentration, equating to $50 \mu \mathrm{g} / \mathrm{ml}$. Following the injection of ULOQ solution, a blank solution was then injected, and the area of analyte appeared in the blank plasma/matrix after the ULOQ injection was measured. At least five injections of ULOQ solution and blank plasma/matrix should be performed to determine the carry over parameters. The area of analyte that appeared in the blank plasma/matrix should not be more than $20 \%$ of LLOQ area.

\subsubsection{Accuracy and precision}

For accuracy and precision, the solutions used were QC sample solutions at low (QCL), medium (QCM) and high (QCH) concentration. In the present work, the concentration of QCL was three times of LLOQ, QC medium was $50 \%$ of the highest concentration, and QCH equates to $80 \%$ of upper limit of quantification (ULOQ) concentration. Moreover, the solution at LLOQ concentration was also used for this parameter. Five replicates of each concentration were prepared on each of three different days. The \%diff and \%CV of each sample injection, both within-run and between runs was determined. In terms of accuracy, the \%diff of each replicate, at each concentration, should be $\pm 15 \%$ and, to determine precision, the $\% \mathrm{CV}$ should not exceed $\pm 15 \%$. The $\%$ diff and $\% \mathrm{CV}$ for the LLOQ concentration however should be $\pm 20 \%$.

\subsubsection{Dilution integrity}

To determine the dilution integrity parameters, spiked plasma or matrix samples with VCN concentrations higher than the ULOQ were used. Accordingly, samples at a concentration of $60 \mu \mathrm{g} / \mathrm{ml}$ were diluted two-fold $(30 \mu \mathrm{g} / \mathrm{ml})$ and four-fold $(15 \mu \mathrm{g} / \mathrm{ml})$, then prepared and extracted using the appropriate method. Five replicates were prepared each day over three days. The acceptance criteria for the dilution integrity parameters were \%diff (accuracy) and \%CV (precision) of $\pm 15 \%$ within and between runs.

\subsubsection{Extraction recovery}

In this study, a relative extraction recovery was obtained by comparing the measured value of extracted samples at QCL, QCM and QCH concentrations with the extracts of spiked blank matrix with the analyte post extraction at low, medium and high concentrations. 


\subsubsection{Stability studies of VCN stock solution and VCN spiked matrices}

Stability studies were performed in plasma, skin and lymph node samples. The following stability studies were carried out: Short term stability of VCN stock solution and working solutions at room temperature $(24 \mathrm{~h})$; freeze and thaw stability ( 3 cycles) of the VCN in the various matrices stored at $-20^{\circ} \mathrm{C}$; long term stability of $\mathrm{VCN}$ stock solution and $\mathrm{VCN}$ in matrices following storage at $-20^{\circ} \mathrm{C}$ for 30 days. The final stability study was carried out in the HPLC autosampler. The extracted VCN samples were injected at $0 \mathrm{~h}$ and stored in the HPLC sample chamber at room temperature for $24 \mathrm{~h}$, and was injected at $24 \mathrm{~h}$.

\subsection{Application of the validated HPLC method in an in vivo model}

Approval for animal experimentation was obtained from the Committee of the Biological Services Unit, Queen's University Belfast under Project Licence PPL 2794 and Personal Licences PIL 1466, 1583 and 1890. All animal experiments were carried out in accordance with the policy of the Federation of European Laboratory Animal Science Associations and the European Convention for the protection of vertebrate animals used for experimental and other scientific purposes, with implementation of the principles of the 3Rs (replacement, reduction and refinement).

Female Sprague-Dawley rats aged 8-10 weeks with average mass of $204 \pm 11 \mathrm{~g}(n=20)$, were acclimatised for 7 days before commencement of the study. The rats were divided into 2 groups, namely oral and intravenous (IV) groups. The animals were administered the same VCN dose of $30 \mathrm{mg} / \mathrm{kg}$. Blood samples were taken at pre-defined intervals: 1, 2, 4, 6, 24 and $48 \mathrm{~h}$ via tail vein bleeds with a maximum of $200 \mu \mathrm{l}$ collected at each sampling point into tubes $(1.5 \mathrm{ml}$ Microtube Conical ${ }^{\circledR}$, Sarstedt, United Kingdom) containing heparin (Wockhardt UK Ltd, Wrexham, UK). Blood sampling intervals adhered to the restrictions of the project licence and the rats were bled no more than two times per day. The plasma separation was carried out by centrifuging the whole blood at 3,000 $\mathrm{g}$ for $10 \mathrm{~min}, 4^{\circ} \mathrm{C}$. Following this centrifugation step, the plasma supernatant was then collected and stored at $-20^{\circ} \mathrm{C}$ prior to use.

Following the collection of the final blood samples, animals were sacrificed. Dorsal skin measuring approximately $2 \mathrm{~cm} \mathrm{x} 2 \mathrm{~cm}$ was excised from the animals. Axillary and inguinal lymph nodes were removed. For skin and lymph node samples, the blood or other contamination was removed by rinsing the samples with phosphate buffered saline (PBS) $\mathrm{pH}$ 7.4 solution and then the samples were blotted using paper towels and stored in a $-20^{\circ} \mathrm{C}$ freezer 
before being processed. Then, the plasma samples obtained were extracted by the selected method, as previously explained in section 2.3. With regards to skin and lymph node samples, VCN was extracted by adding each organ (skin or lymph node) (100 mg) to $900 \mu \mathrm{l}$ of water. Then, it was processed using a tissue homogeniser, as previously outlined in section 2.2, and supernatants were collected. An aliquot $(50 \mu \mathrm{l})$ of this supernatant was analysed via HPLC. To ensure that the drug was completely extracted from the tissue samples, a second extraction was carried out. Water $(1 \mathrm{ml})$ was added to the residue obtained at the end of the first extraction and this was then processed as described. The supernatant from this second extraction was also collected and an aliquot ( $50 \mu \mathrm{l})$ was injected and analysed via HPLC.

\subsection{Statistical analysis}

All data presented was reported as mean \pm standard deviation (SD). The mean, SD, linear regression analysis, $\% \mathrm{RSD}$ and $\% \mathrm{CV}$ of each sample in the validation method were processed using Microsoft ${ }^{\circledR}$ Excel $^{\circledR} 2016$ (Microsoft Corporation, Redmond, USA). In terms of pharmacokinetic profiles and parameters, a non-compartmental analysis of plasma samples was performed using PKSolver (add-in program of Microsoft Excel). Statistical analysis in this study was carried out using GraphPhad Prism ${ }^{\circledR}$ version 8.3.0 (GraphPad Software Inc., San Diego, California), with the significance set at $p<0.05$. In terms of VCN oral bioavailability, it was calculated using area under curve (AUC) for oral and IV administration using the following equation:

$$
F={ }^{A U C_{\text {oral }}} /_{A U C_{I V}} \times 100 \%
$$

\section{Results and Discussion}

\subsection{Chromatographic condition}

The development of the bioanalytical method in this study was carried out using RP-HPLC with gradient method set at $215 \mathrm{~nm}$. In terms of mobile phase, the $\mathrm{pH}$ of phosphate buffer used was 2.5. Based on its chemical structure, $\mathrm{VCN}$ is an amphoteric drug that has both carboxylic and amino groups. These functional groups are included into the ionisable functional groups. At $\mathrm{pH}$ values between 4 and 8 , both carboxylic and amino groups are ionised, leading to shortened retention of this drug in the stationary phase. So, this range of $\mathrm{pH}$ was not appropriate to be selected as mobile-phase $\mathrm{pH}$ for such compounds. At higher $\mathrm{pH}(\mathrm{pH}>8)$, the amino 
group becomes a neutral group but the carboxylic group is fully ionised. In contrast, at $\mathrm{pH}$ lower than 4, acidic group becomes neutral and the amino groups are fully protonated. Thus, $\mathrm{pH}$ of mobile phase that provides either the least or the highest ionisation of the samples is the most applicable for amphoteric compounds. In order to obtain a sharp peak, an amino modifier was added into the aqueous phase. One amine modifier which has been generally used for improving peak shape of analytes in RP-HPLC is TEA. Amine groups of VCN are positively charged at $\mathrm{pH}<8$ and the secondary interaction of amines with silanol groups may occur. The addition of TEA into the aqueous phase may, therefore, hinder the secondary interaction between these ionised amine groups and free silanol groups of stationary phases, thus maintaining the peak shape of amino groups-containing substances which are analysed using low $\mathrm{pH}$ mobile phase (acidic). For organic solvent, the mixture of methanol and acetonitrile was used. The type and content of organic modifier can interfere with the degree of ionisation of ionisable compounds. As mentioned previously, VCN has some ionisable functional groups, so the retention mechanism of this drug is dependent on both $\mathrm{pH}$ and organic modifier. $\mathrm{LC}$ analysis under gradient method for quantifying $\mathrm{VCN}$ in biological samples has been also reported in some previous studies $[9,12,21,23]$.

\subsection{Selection of sample preparation and drug extraction}

Four methods were evaluated in the selection of plasma sample preparation. The extraction recovery for each method is illustrated in Figure 1 below. Results revealed that Method A showed recovery less than $10 \%$. There may have been interactions between the VCN amino acid residues and plasma proteins resulting in a higher molecular weight product that could not pass through the filter membrane ( $3 \mathrm{kD}$ cut-offs). Evaporation of the supernatant (Method D) was also shown to lead to a reduction in extraction efficiency. Evaporation may dehydrate the peptide constituent of VCN leading to drug loss. Additionally, dehydration of the liquid component, of plasma water and organic solvent, may destabilise the peptide structure and decrease the half-life of the peptide [24]. On the other hand, Method C (protein precipitation with the additional of water) which was previously reported by Shi et al. [22], gave the second highest extraction recovery when compared to other methods tested in this study. The highest extraction recovery was achieved using Method B, where VCN was extracted by using a simple protein precipitation method with methanol only. Therefore, Method B was selected for further studies because it was simple, quick and gave the highest recovery of drug. 


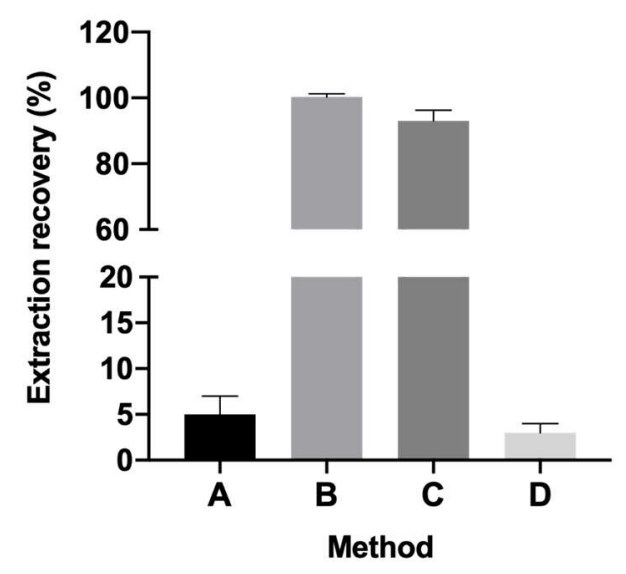

Figure 1. Bar graphs showing the drug recovery percentage of each method when extracting VCN from plasma (means $\pm \mathrm{SD}, \mathrm{n}=3$ ).

\subsection{Method validation}

\subsubsection{Selectivity}

Based on the results presented in Figure 2, the extraction method was selective for analysing VCN in different biological matrices. No interferences were observed at the VCN retention time (approximately $8.20 \mathrm{~min}$ ) in any of the blank matrices injected.

\subsubsection{Linearity of calibration curve}

In this study, calibration curve standards in different matrices were prepared using 7 drug concentrations and one blank per day for three consecutive days. Table 3 summarises the concentration ranges, slopes, $y$-intercept and correlation coefficient $\left(\mathrm{R}^{2}\right)$ values of each matrix. All concentrations in each matrix tested showed $\% \mathrm{CV}<8 \%$ and $\%$ diff not more than $\pm 15 \%$, and \%diff for LLOQ not more than $\pm 20 \%$ for each replicate on three different days. Furthermore, the $\mathrm{R}^{2}$ value obtained in all matrices was close to 1 , which indicated the linearity of the concentration in the test system.

\subsubsection{Lower limit of quantification (LLOQ)}

The LLOQ values of VCN in plasma, skin and lymph node were $0.1 \mu \mathrm{g} / \mathrm{ml}, 0.05 \mu \mathrm{g} / \mathrm{ml}$ and $0.05 \mu \mathrm{g} / \mathrm{ml}$, respectively. The LLOQ determined for the plasma matrix in this study was lower than LLOQ from a range of previously published works, which reported LLOQs of $5 \mu \mathrm{g} / \mathrm{ml}$ [13], $0.5 \mu \mathrm{g} / \mathrm{ml}$ [25] and $0.25 \mu \mathrm{g} / \mathrm{ml}$ [14], respectively. A method HPLC-UV method for quantifying VCN in the skin samples, was previously reported by Farin et al. [25], however, the LLOQ obtained $(0.5 \mu \mathrm{g} / \mathrm{ml})$ was also higher than LLOQs obtained in this study. Moreover, the LLOQ obtained for skin and lymph node samples were also low when compared to the 
LLOQs mentioned above. These results revealed that the method was sensitive to analyse VCN in different biological matrices.
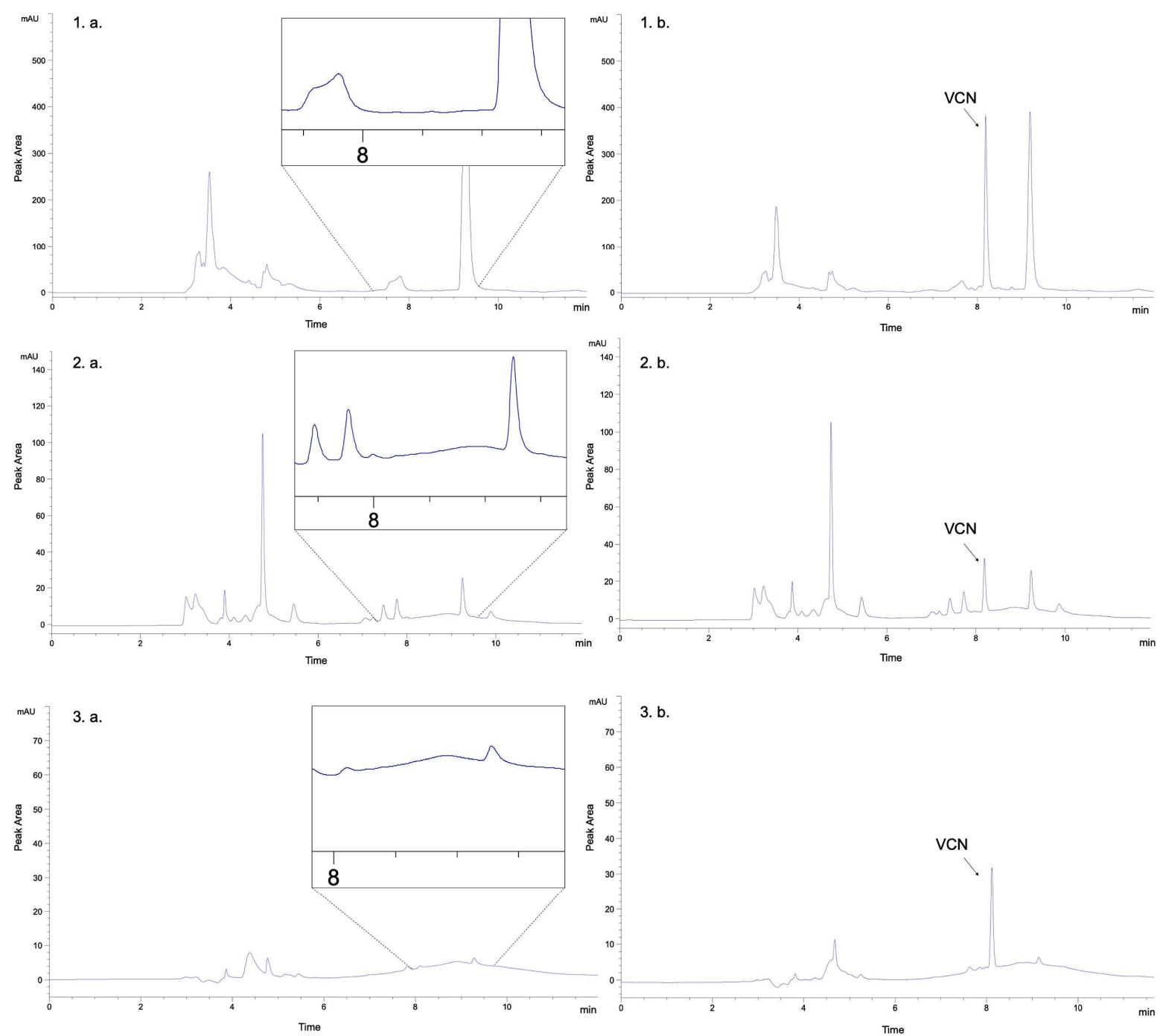

Figure 2. Representative HPLC chromatograms of blank: (1.a) plasma, (2.a) skin and (3.a) lymph node. Chromatograms of plasma, skin and lymph spiked with VCN standard solution (1.b) $50 \mu \mathrm{g} / \mathrm{ml}$, (2.b) $1 \mu \mathrm{g} / \mathrm{ml}$ and (3.b) $1 \mu \mathrm{g} / \mathrm{ml}$, respectively.

Table 3. Linear regression of VCN standard solution in different matrices.

\begin{tabular}{lllll}
\hline Matrix & Concentration range $(\boldsymbol{\mu g} / \mathbf{m l})$ & Slope & $\boldsymbol{y}$-intercept & $\mathbf{R}^{\mathbf{2}}$ \\
\hline Plasma & $0.1-50$ & 51.85 & -0.57 & 0.9998 \\
Skin & $0.05-50$ & 109.45 & -0.23 & 0.9999 \\
Lymph & $0.05-50$ & 109.36 & -0.23 & 0.9995 \\
\hline
\end{tabular}




\subsubsection{Carry over}

For carry over assessment, no peaks appeared at the VCN retention time or any other peaks with values of more than $20 \%$ LLOQ area, in all matrices after the injection of ULOQ solutions. Thus, it was concluded that there was no carry over observed in this method.

\subsubsection{Accuracy and precision}

Accuracy and precision of VCN measurement using the optimised method in plasma, skin and lymph matrices are summarised in Table 4 . These results showed that the method is accurate and precise based on EMEA 2011 and FDA 2018 guidelines, where the \%diff and \%CV withinand between-runs of the measurement should not exceed 15\% for QCL, QCM and QCH and should not be more than $20 \%$ for LLOQ.

\subsubsection{Dilution integrity}

The dilution integrity accuracy of VCN measurements at a range of different concentrations in plasma, skin and lymph node matrices were 92-110\%, 96-108\% and 93-111\%, respectively. All diluted samples exhibited acceptable accuracy which were not more than $\pm 15 \%$ of the theoretical value in any case. The precision of the diluted samples $(\% \mathrm{CV})$ was in the ranges of $1.0-8.9 \%$, all less than $15 \%$. These results revealed that samples with concentrations higher that the ULOQ can be diluted and then accurately measured/quantified using this method.

\subsubsection{Extraction recovery}

The extraction recovery of VCN from all matrices is summarised in Table 5. The recovery obtained in this study was in the range of $85-115 \%$. The FDA bioanalytical guidelines indicate the importance of efficiency, consistency and reproducibility of recovery, conceding that the recovery of analyte in bioanalytical method does not need to be $100 \%$. 
Table 4. Within-run $(n=5)$ and between-run $(n=15)$ accuracy and precision of VCN in plasma, skin and lymph node matrices.

\begin{tabular}{|c|c|c|c|c|c|c|c|c|c|}
\hline \multirow{3}{*}{ Sample } & \multirow{3}{*}{$\begin{array}{l}\text { Concentration } \\
(\mu \mathrm{g} / \mathrm{ml})\end{array}$} & \multicolumn{6}{|c|}{ Within-run } & \multirow{2}{*}{\multicolumn{2}{|c|}{ Between Run }} \\
\hline & & \multicolumn{2}{|l|}{ Day 1} & \multicolumn{2}{|l|}{ Day 2} & \multicolumn{2}{|l|}{ Day 3} & & \\
\hline & & $\begin{array}{l}\text { Accuracy } \\
\text { (\%diff) }\end{array}$ & $\begin{array}{l}\text { Precision } \\
(\% \mathrm{CV})\end{array}$ & $\begin{array}{l}\text { Accuracy } \\
\text { (\%diff) }\end{array}$ & $\begin{array}{l}\text { Precision } \\
(\% \mathrm{CV})\end{array}$ & $\begin{array}{l}\text { Accuracy } \\
\text { (\%diff) }\end{array}$ & $\begin{array}{l}\text { Precision } \\
(\% \mathrm{CV})\end{array}$ & $\begin{array}{l}\text { Accuracy } \\
\text { (\%diff) }\end{array}$ & $\begin{array}{l}\text { Precision } \\
(\% \mathrm{CV})\end{array}$ \\
\hline \multirow{4}{*}{ Plasma } & 0.1 (LLOQ) & -2.7 & 9.5 & 0.8 & 7.0 & 9.1 & 4.6 & 2.4 & 5.9 \\
\hline & 0.3 (QCL) & -2.5 & 8.0 & 2.0 & 5.8 & 7.9 & 2.8 & 2.5 & 5.1 \\
\hline & 25 (QCM) & 7.5 & 2.4 & -3.6 & 2.0 & 7.9 & 1.8 & 1.4 & 5.5 \\
\hline & $40(\mathrm{QCH})$ & 7.8 & 0.9 & -1.5 & 2.9 & 0.2 & 3.3 & 2.2 & 4.9 \\
\hline \multirow{4}{*}{ Skin } & 0.05 (LLOQ) & 6.8 & 8.1 & 5.0 & 6.5 & 5.4 & 5.7 & 5.7 & 0.9 \\
\hline & 0.15 (QCL) & 0.2 & 5.0 & -0.9 & 5.0 & 2.8 & 3.3 & 0.7 & 1.9 \\
\hline & 25 (QCM) & 2.2 & 1.2 & 3.0 & 2.7 & 2.8 & 2.0 & 2.9 & 0.6 \\
\hline & $40(\mathrm{QCH})$ & 2.6 & 1.5 & 10.7 & 2.0 & 3.1 & 2.6 & 5.5 & 4.3 \\
\hline \multirow{4}{*}{ Lymph node } & 0.05 (LLOQ) & -3.5 & 8.4 & 8.3 & 5.4 & 10.4 & 4.4 & 5.1 & 7.1 \\
\hline & 0.15 (QCL) & -2.1 & 3.0 & 1.5 & 2.9 & 1.7 & 3.9 & 0.4 & 2.1 \\
\hline & 25 (QCM) & 5.2 & 2.7 & 1.0 & 1.2 & 1.7 & 0.9 & 1.8 & 3.0 \\
\hline & $40(\mathrm{QCH})$ & 7.4 & 2.9 & 8.9 & 2.4 & -1.8 & 1.2 & 4.8 & 5.5 \\
\hline
\end{tabular}


Table 5. Extraction recovery ranges of VCN from all matrices $(n=15)$

\begin{tabular}{lll}
\hline Matrix & QC & Extraction Recovery Ranges (\%) \\
\hline Plasma & Low $(0.3 \mu \mathrm{g} / \mathrm{ml})$ & $88-113$ \\
& Medium $(25 \mu \mathrm{g} / \mathrm{ml})$ & $94-111$ \\
\multirow{2}{*}{ Skin } & High $(40 \mu \mathrm{g} / \mathrm{ml})$ & $96-109$ \\
& Low $(0.15 \mu \mathrm{g} / \mathrm{ml})$ & $94-108$ \\
& Medium $(25 \mu \mathrm{g} / \mathrm{ml})$ & $100-107$ \\
Lymph node & High $(40 \mu \mathrm{g} / \mathrm{ml})$ & $99-113$ \\
& Low $(0.15 \mu \mathrm{g} / \mathrm{ml})$ & $94-106$ \\
& Medium $(25 \mu \mathrm{g} / \mathrm{ml})$ & $98-108$ \\
& High $(40 \mu \mathrm{g} / \mathrm{ml})$ & $97-112$ \\
\hline
\end{tabular}

\subsubsection{Stability study of VCN in different matrices}

The stability study of VCN was carried out in ultrapure water (stock solution) and the three biological matrices at QCL and QCH concentrations. The data presented in Table 6 summarises the stability studies (short term, long term, freeze-thaw and autosampler) of VCN in all matrices. The short- and long-term stability results showed that VCN was stable for at least 30 days both in stock solution and in all biological matrices tested, based on the \%diff of each measurement which did not exceed $\pm 15 \%$ of the value obtained for day 0 . In terms of freeze-thaw stability, VCN was still stable in plasma, skin and lymph node samples after the third cycle of freezethaw. Furthermore, VCN also remained stable based on the autosampler stability study over 24 $\mathrm{h}$ of storage in the HPLC sample chamber. The short- and long-term stability results showed that VCN was stable at least 30 days both in stock solution and all matrices tested based on the $\%$ drug recovered in each measurement (Table 7 ). They did not exceed $\pm 15 \%$ of the values obtained on day- 0 .

Table 6. Stability of VCN at different QC concentrations in all matrices which showed by the ranges of drug recovered percentage obtained compared to the value at the initial conditions $(n=3)$.

\begin{tabular}{|c|c|c|c|c|c|}
\hline \multirow[b]{2}{*}{ Matrix } & \multirow{2}{*}{$\begin{array}{l}\text { Theoretical } \\
\text { Concentration } \\
(\mu \mathrm{g} / \mathrm{ml})\end{array}$} & \multicolumn{4}{|c|}{ Drug Recovery Ranges (\%) } \\
\hline & & $\begin{array}{l}\text { Short term } \\
(24 \mathrm{~h})\end{array}$ & $\begin{array}{l}\text { Long term } \\
\text { (30 days) } \\
\end{array}$ & $\begin{array}{l}\text { Freeze-thaw } \\
(\text { cycle-3) }\end{array}$ & $\begin{array}{l}\text { Autosampler } \\
(24 \text { h) }\end{array}$ \\
\hline \multirow[t]{2}{*}{ Plasma } & 0.3 & $107-110$ & $97-101$ & $104-107$ & $98-105$ \\
\hline & 40 & $104-109$ & $101-110$ & $101-107$ & $103-107$ \\
\hline \multirow[t]{2}{*}{ Skin } & 0.15 & $94-99$ & $92-101$ & $92-98$ & $95-101$ \\
\hline & 40 & $94-102$ & $94-104$ & $98-103$ & $98-105$ \\
\hline \multirow[t]{2}{*}{ Lymph node } & 0.15 & $91-98$ & $90-98$ & $91-104$ & $92-98$ \\
\hline & 40 & $94-104$ & $97-103$ & $99-104$ & $94-104$ \\
\hline
\end{tabular}


Table 7. Percentage of drug recovered from VCL stock solution in water after $24 \mathrm{~h}$ and 30 days storage $(\mathrm{n}=3)$.

\begin{tabular}{lll}
\hline \multirow{2}{*}{ Theoretical Concentration $(\boldsymbol{\mu g} / \mathbf{m l})$} & \multicolumn{2}{l}{ Drug Recovery Ranges $(\mathbf{\%})$} \\
\cline { 2 - 3 } & Short term $(\mathbf{2 4} \mathbf{~ h})$ & Long term (30 days) \\
\hline 0.15 & $90-99$ & $96-102$ \\
0.30 & $95-102$ & $93-102$ \\
40 & $96-97$ & $99-101$ \\
\hline
\end{tabular}

\subsubsection{Animal studies}

The validated bioanalytical method, with associated sample preparation parameters, was employed to determine the pharmacokinetics of $\mathrm{VCN}$ in rat plasma and its biodistribution in the skin and lymph nodes of treated animals. In terms of analyte extraction from skin and lymph node samples, VCN was only found in the first supernatant, equating to $100 \%$ recovery (98$101 \%)$. This demonstrated that VCN was completely extracted from the samples using only one extraction step. Thus, this one step extraction procedure was employed for extracting VCN from the skin and lymph node samples in the animal study.

The data in Figure 3 illustrates the mean plasma concentrations of VCN after administration of IV bolus injection or oral solution of drug. Following the construction of the mean plasma concentration and time profiles, the pharmacokinetics parameters were processed using the PKSolver, as previously explained, using a non-compartmental pharmacokinetic analysis. Then the following parameters were calculated: half-life $\left(t_{1 / 2}\right)$, time to reach maximum concentration $\left(\mathrm{t}_{\max }\right)$, maximum concentration $\left(\mathrm{C}_{\max }\right)$, area under curve from $0 \mathrm{~h}$ to $48 \mathrm{~h}\left(\mathrm{AUC}_{0}\right.$ t), area under curve from $0 \mathrm{~h}$ to infinity $\left(\mathrm{AUC}_{0 \text {-inf }}\right)$ and mean residence time $(\mathrm{MRT})$. The pharmacokinetic parameter summary is provided in Table 8 .
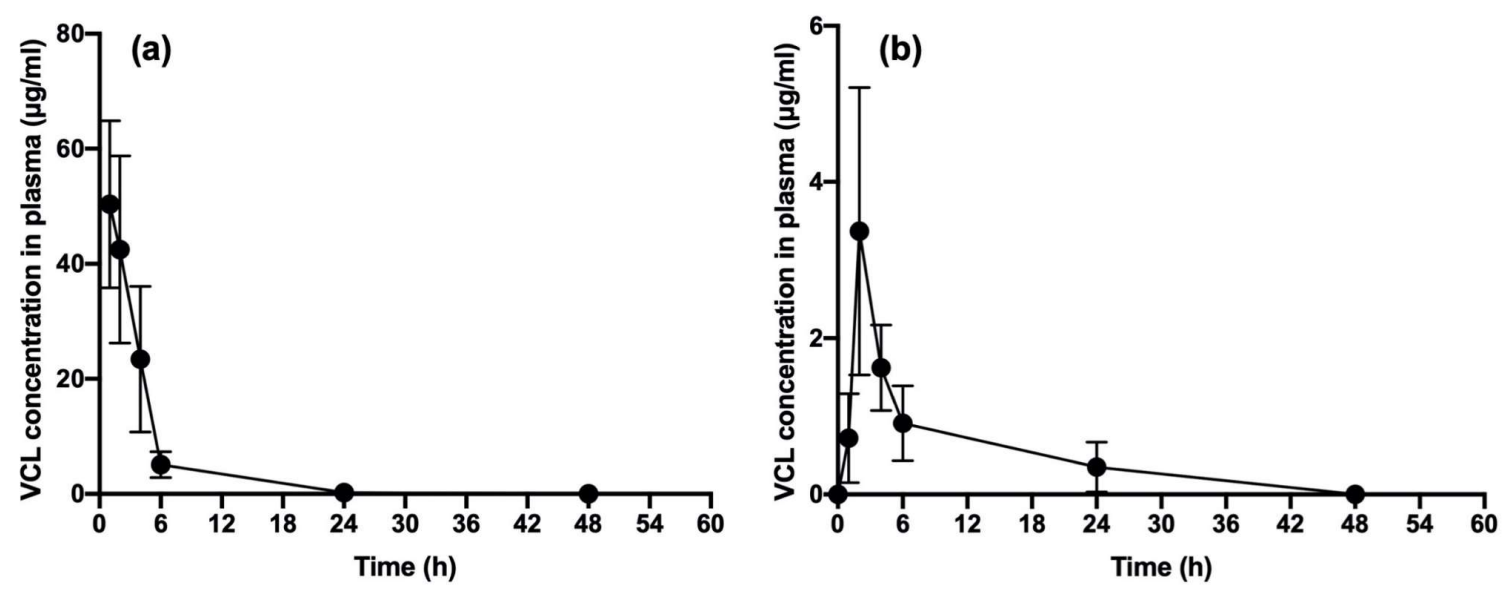

Figure 3. Plasma concentration of VCN after administration of (a) IV injection and (b) oral solution quantified with the validated method. (Means $\pm \mathrm{SD}, \mathrm{n}=5$ ). 
Table 8. Summary of pharmacokinetic parameters after the administration of IV bolus injection or oral solution of $\mathrm{VCN}$ to rats (Mean $\pm \mathrm{SD}, \mathrm{n}=5$ ).

\begin{tabular}{lll}
\hline Parameter & Intravenous Injection & Oral solution \\
\hline $\mathrm{t}_{1 / 2}(\mathrm{~h})$ & $3.12 \pm 0.10$ & $4.40 \pm 0.28$ \\
$\mathrm{t}_{\max }(\mathrm{h})$ & $1.00 \pm 0.00$ & $2.00 \pm 0.00$ \\
$\mathrm{C}_{\max }(\mu \mathrm{g} / \mathrm{ml})$ & $50.34 \pm 14.50$ & $3.37 \pm 1.84$ \\
$\mathrm{AUC}_{0-\mathrm{t}}(\mu \mathrm{g} . \mathrm{h} / \mathrm{ml})$ & $270.80 \pm 97.18$ & $30.50 \pm 9.18$ \\
$\mathrm{AUC}_{0-\mathrm{inf}}(\mu \mathrm{g} . \mathrm{h} / \mathrm{ml})$ & $270.80 \pm 97.18$ & $30.50 \pm 9.18$ \\
$\mathrm{MRT}(\mathrm{h})$ & $3.45 \pm 0.41$ & $9.43 \pm 4.69$ \\
\hline
\end{tabular}

The dose of VCN administered in this study was $30 \mathrm{mg} / \mathrm{kg}$ for both IV injection or oral solution. This dose was the recommended dose for IV injection and infusion to reach rapid serum concentrations [26]. Following IV bolus injection, VCN was completely eliminated from rat plasma after $24 \mathrm{~h}$ (Figure 3). An administrated dose of $30 \mathrm{mg} / \mathrm{kg} \mathrm{VCN}$ led to $\mathrm{C}_{\max }$ of $50.34 \pm$ $14.50 \mu \mathrm{g} / \mathrm{ml}$ at $1 \mathrm{~h}$, with a decrease to approximately half that concentration at approximately

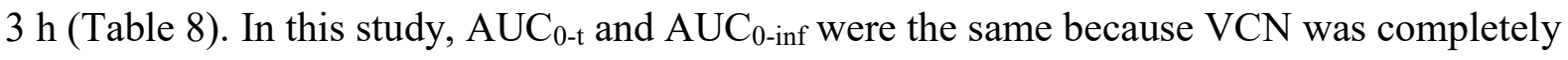
eliminated from the rat circulation at $48 \mathrm{~h}$ with MRT $3.45 \pm 0.41 \mathrm{~h}$. The results obtained in this present work are in line with that reported by Okochi and Nakano [27] who investigated the administration of VCN IV injection at a dose of $15 \mathrm{mg} / \mathrm{kg}$ to male Wistar rats. They reported that a VCN concentration equating to $25 \mu \mathrm{g} / \mathrm{ml}$ was reached $1 \mathrm{~h}$ post-administration and decreased to $\sim 13 \mu \mathrm{g} / \mathrm{ml}$ at approximately $3-4 \mathrm{~h}$. Moreover, the $\mathrm{AUC}_{0 \text {-inf }}$ reported here was twice as high as the value obtained by Okochi and Nakano $(143.9 \pm 14.4 \mu \mathrm{g} . \mathrm{h} / \mathrm{ml})$. There is a linear relationship between $\mathrm{C}_{\max }$ and $\mathrm{AUC}_{0 \text {-inf }}$ of $\mathrm{VCN}$ with the dose administered. A faster $\mathrm{t}_{1 / 2}$ was also reported by Blaskovich et al. who carried out a study with mice and IV injection of VCN at the dose of $2 \mathrm{mg} / \mathrm{kg}$ [28]. They reported that the $\mathrm{t}_{1 / 2}$ was $0.64 \mathrm{~h}$ and VCN concentration at 1 $\mathrm{h}$ was $0.76 \pm 0.14 \mu \mathrm{g} / \mathrm{ml}$. Regardless of the dose administered, the drug clearance in smaller animals, such as mice, is often quicker than in rats or humans [15]. This faster clearance may be associated with the difference of drug metabolism behaviour in the smaller animals.

In terms of oral VCN administration, $\mathrm{C}_{\max }$ was achieved at $2 \mathrm{~h}$, with a concentration of $3.37 \pm$ $1.84 \mu \mathrm{g} / \mathrm{ml}$. Moreover, the VCN half-life in this study was approximately $4.5 \mathrm{~h}$ with MRT in the body circulation up to $9.43 \pm 4.69 \mathrm{~h}$. The $\mathrm{AUC}_{0 \text {-inf }}$ of $\mathrm{VCN}$ after $48 \mathrm{~h}$-study was $30.50 \pm$ $9.18 \mu \mathrm{g} . \mathrm{h} / \mathrm{ml}$. Based on these results, the absolute bioavailability of oral VCN can be calculated using equation 1 . When compared to IV injection, oral bioavailability of VCN was $11.26 \%$. Oral bioavailability data for VCN is quite limited, due to its low absorption in the 
gastrointestinal tract. An investigations of VCN oral bioavailability were reported by Shibata et al. [29] and Yamazaki et al. [30]. The high oral bioavailability of VCN (54.5\%) reported by Yamazaki et al., was a result of the colitis condition in colitis model rats. Shibata et al., however, who administered $20 \mathrm{mg} / \mathrm{kg}$ of $\mathrm{VCN}$ to male Wistar rats, found that the bioavailability of VCN was $0.069 \%$ over a $6 \mathrm{~h}$ study. Their results indicated that VCN was not completely eliminated from rat plasma at $6 \mathrm{~h}$ which might affect the AUCs, both of $\mathrm{AUC}_{0-\mathrm{t}}$ and $\mathrm{AUC}_{0 \text {-inf, }}$ resulting in the difference of $\mathrm{F}$ value obtained. Furthermore, the $\mathrm{VCN}$ dose and the gender of the rats used were different from the current study and, as previously mentioned, some factors relating to the in vivo model used can affect the reported pharmacokinetic parameters [15]. The biodistribution of VCN in the rat skin and lymph nodes after $24 \mathrm{~h}$ and 48 h of study are presented in Table 9.

Table 9. VCN concentrations in the skin and lymph nodes after administration of VCN via oral or IV routes. $($ mean $\pm \mathrm{SD}, \mathrm{n}=3$ )

\begin{tabular}{llll}
\hline Sample & Administration route & Concentration $(\boldsymbol{\mu g} / \mathbf{g})$ & \\
& & $\mathbf{2 4} \mathbf{~ h}$ & $\mathbf{4 8 ~ h}$ \\
\hline Skin & Oral & $0.27 \pm 0.11$ & $0.13 \pm 0.06$ \\
& IV & $0.07 \pm 0.04$ & Not found \\
\multirow{2}{*}{ Lymph node } & Oral & $0.80 \pm 0.24$ & $0.11 \pm 0.05$ \\
& IV & $0.06 \pm 0.01$ & $0.05 \pm 0.01$ \\
\hline
\end{tabular}

As can be seen in Table 9, the VCN was found in both skin and lymph node samples at $24 \mathrm{~h}$, with concentrations of less than $1 \mu \mathrm{g} / \mathrm{g}$. However, the IV route of administration resulted in lower VCN concentrations than the oral route. This may be due to the fast clearance of VCN in the plasma after the IV bolus administration and VCN excretion via glomerular filtration in the kidney. To elaborate on this, the MRT value in Table 8 suggests that VCN was retained for longer in the rat body when the drug was administered orally, specifically, approximately three times longer than when administered via the IV route. It is worth noting that supplementary to the organs investigated in the current work, VCN has also been reported to be distributed to a range of other organs including CSF [4], heart [5], lungs [6] and skin ISF [7]. VCN concentration in the skin has been previously reported by Farin et al. [25], but the samples (chest and leg skins) were obtained from patients undergoing cardiopulmonary bypass. Therefore, to conclude, the results of the present study help to complete the VCN biodistribution data set, with specific reference to skin and lymph node data sets. 


\section{Conclusions}

The work presented here reports a simple and robust sample preparation and HPLC-UV method for quantification of VCN in a range of biological matrices. This study has provided a reliable, selective and sensitive bioanalytical method for $\mathrm{VCN}$ which was validated based on EMEA and FDA bioanalytical guidelines. The validated HPLC-UV method was successfully employed in a pharmacokinetic and biodistribution study of VCN in rats after oral and IV bolus administration. In addition, the method gave lower LLOQ in plasma $(0.1 \mu \mathrm{g} / \mathrm{ml})$ and skin/lymph node samples $(0.05 \mu \mathrm{g} / \mathrm{ml})$, when compared to previously reported HPLC-UV methods. The use of this new bioanalytical method, therefore, serves to enhance understanding of quantification and determination of the pharmacokinetics and biodistribution of VCN in future clinical and therapeutic drug monitoring applications.

\section{Acknowledgements}

This work was supported by The Indonesian Endowment Fund for Education (Lembaga Pengelola Dana Pendidikan / LPDP) scholarship. The authors also thank to Mr Gareth Geddis from the Biological Services Unit (BSU), Queen's University Belfast for his help with in vivo experimentation.

\section{References}

[1] P.N.K. Wijesekara, W.W. Kumbukgolla, J.A.A.S. Jayaweera, D. Rawat, Review on usage of vancomycin in livestock and humans: Maintaining its efficacy, prevention of resistance and alternative therapy, Vet. Sci. 4 (2017) 1-11. https://doi.org/10.3390/vetsci4010006.

[2] E.J. Filippone, W.K. Kraft, J.L. Farber, The Nephrotoxicity of Vancomycin, Clin. Pharmacol. Ther. 102 (2017) 459-469. https://doi.org/10.1002/cpt.726.

[3] D.M. Parente, K.L. Laplante, Section 7: Anti-infective therapy 145, in: Infect. Dis., Auckland, 2017: pp. 1249-1255.e2.

[4] M. Ishikawa, S. Yamazaki, T. Suzuki, M. Uchida, Y. Iwadate, I. Ishii, Correlation between vancomycin penetration into cerebrospinal fluid and protein concentration in cerebrospinal fluid/serum albumin ratio, J. Infect. Chemother. 25 (2019) 124-128. https://doi.org/10.1016/j.jiac.2018.10.013.

[5] R. Jashari, F. Faucon, B. van Hoeck, S. de Gelas, Y. Fan, S. Vandenbulcke, Determination of residual antibiotics in cryopreserved heart valve allografts, Transfus. Med. Hemotherapy. 38 (2011) 379-386. https://doi.org/10.1159/000334706. 
[6] M.J.J. Valle, F.G. López, A.S. Navarro, Development and validation of an HPLC method for vancomycin and its application to a pharmacokinetic study, J. Pharm. Biomed. Anal. 48 (2008) 835-839. https://doi.org/10.1016/j.jpba.2008.05.040.

[7] Y. Ito, Y. Inagaki, S. Kobuchi, K. Takada, T. Sakaeda, Therapeutic drug monitoring of vancomycin in dermal interstitial fluid using dissolving microneedles, Int. J. Med. Sci. 13 (2016) 271-276. https://doi.org/10.7150/ijms.13601.

[8] M.M.D.C. Vila, R.M. de Oliveira, M.M. Gonçalves, M. Tubino, Analytical methods for vancomycin determination in biological fluids and in pharmaceuticals, Quim. Nova. 30 (2007) 395-399. https://doi.org/10.1590/S0100-40422007000200029.

[9] N.B. Andriguetti, L.L. Lisboa, S.R. Hahn, L.R. Pagnussat, M. V. Antunes, R. Linden, Simultaneous determination of vancomycin and creatinine in plasma applied to volumetric absorptive microsampling devices using liquid chromatography-tandem mass spectrometry, J. Pharm. Biomed. Anal. 165 (2019) 315-324. https://doi.org/10.1016/j.jpba.2018.12.023.

[10] G. Brandhorst, M. Oellerich, G. Maine, P. Taylor, G. Veen, P. Wallemacq, Liquid chromatography-Tandem mass spectrometry or auomated immunoassays: What are the future trends in therapeutic drug monitoring?, Clin. Chem. 58 (2012) 821-825. https://doi.org/10.1373/clinchem.2011.167189.

[11] P. Favetta, J. Guitton, N. Bleyzac, C. Dufresne, J. Bureau, New sensitive assay of vancomycin in human plasma using high-performance liquid chromatography and electrochemical detection, J. Chromatogr. B Biomed. Sci. Appl. 751 (2001) 377-382. https://doi.org/10.1016/S0378-4347(00)00484-9.

[12] K.H. Abu-Shandi, Determination of vancomycin in human plasma using highperformance liquid chromatography with fluorescence detection, Anal. Bioanal. Chem. 395 (2009) 527-532. https://doi.org/10.1007/s00216-009-2948-9.

[13] M. Zhang, X.L. Huang, W. Yahui, C. Shi, P. Pei, J. Yang, Q. Dong, X. Cui, A rapid and simple UPLC method for serum vancomycin determination in pediatric patients undergoing continuous infusion or intermittent infusion of vancomycin, J. Pharm. Biomed. Anal. 174 (2019) 214-219. https://doi.org/10.1016/j.jpba.2019.05.056.

[14] M. Usman, G. Hempel, Development and validation of an HPLC method for the determination of vancomycin in human plasma and its comparison with an immunoassay (PETINIA), Springerplus. 5 (2016) 1-7. https://doi.org/10.1186/s40064016-1778-4.

[15] M. Zhao, A.J. Lepak, D.R. Andes, Animal models in the pharmacokinetic / 
pharmacodynamic evaluation of antimicrobial agents, Bioorg. Med. Chem. 24 (2016) 6390-6400.

[16] S. Zafar, A. Decastro, S. Pal, J. Pandav, N. Kanaparthy, Vancomycin-induced DRESS syndrome, Ann. Allergy, Asthma Immunol. 124 (2020) 107-108.

https://doi.org/10.1016/j.anai.2019.09.002.

[17] European Medicines Agency. Guideline on Bioanalytical Method Validation. https://www.ema.europa.eu/en/documents/scientific-guideline/guideline-bioanalyticalmethod-validation_en.pdf, 2011,(Accessed on August 2018).

[18] Food and Drug Administration. Center for Drug Evaluation and Research, Guidance for Industry: Bioanalytical Methods Validation. USA.

https://www.fda.gov/downloads/drugs/guidances/ucm070107.Pdf, 2018 , (Accessed on September 2018).

[19] A.D. Permana, I.A. Tekko, H.O. McCarthy, R.F. Donnelly, New HPLC-MS method for rapid and simultaneous quantification of doxycycline, diethylcarbamazine and albendazole metabolites in rat plasma and organs after concomitant oral administration, J. Pharm. Biomed. Anal. 170 (2019) 243-253. https://doi.org/10.1016/j.jpba.2019.03.047.

[20] B. Pamornpathomkul, T. Ngawhirunpat, I.A. Tekko, L. Vora, H.O. McCarthy, R.F. Donnelly, Dissolving polymeric microneedle arrays for enhanced site-specific acyclovir delivery, Eur. J. Pharm. Sci. 121 (2018) 200-209. https://doi.org/10.1016/j.ejps.2018.05.009.

[21] L. Javorska, L.K. Krcmova, P. Solich, M. Kaska, Simple and rapid quantification of vancomycin in serum, urine and peritoneal/pleural effusion via UHPLC-MS/MS applicable to personalized antibiotic dosing research, J. Pharm. Biomed. Anal. 142 (2017) 59-65. https://doi.org/10.1016/j.jpba.2017.04.029.

[22] M. Shi, X. Zhao, T. Wang, L. Yin, Y. Li, A LC-MS-MS assay for simultaneous determination of two glycopeptides and two small molecule compounds in human plasma, J. Chromatogr. Sci. 56 (2018) 828-834. https://doi.org/10.1093/chromsci/bmy060.

[23] M.J. Ahsman, E.D. Wildschut, D. Tibboel, R.A. Mathot, Microanalysis of $\beta$-lactam antibiotics and vancomycin in plasma for pharmacokinetic studies in neonates, Antimicrob. Agents Chemother. 53 (2009) 75-80. https://doi.org/10.1128/AAC.00636-08.

[24] S. Ohtake, S. Feng, E. Shalaev, Effect of Water on the Chemical Stability of 
Amorphous Pharmaceuticals: 2. Deamidation of Peptides and Proteins, J. Pharm. Sci. 107 (2018) 42-56. https://doi.org/10.1016/j.xphs.2017.09.003.

[25] D. Farin, G.A. Piva, I. Gozlan, R. Kitzes-Cohen, A modified HPLC method for the determination of vancomycin in plasma and tissues and comparison to FPIA (TDX), J. Pharm. Biomed. Anal. 18 (1998) 367-372. https://doi.org/10.1016/S07317085(98)00095-8.

[26] J.K. Ortwine, E.J. Zasowski, J.M. Pogue, C. Hanni, C. Giuliano, A.M. Casapao, R. Mynatt, M.J. Rybak, Relationship Status between Vancomycin Loading Dose and Treatment Failure in Patients with MRSA Bacteremia: It's Complicated, Infect. Dis. Ther. 8 (2019) 627-640. https://doi.org/10.1007/s40121-019-00268-3.

[27] H. Okochi, M. Nakano, Pharmacokinetics of vancomycin after intravenous administration of a W/O/W emulsion to rats, Drug Deliv. 4 (1997) 167-172. https://doi.org/10.3109/10717549709051888.

[28] M.A.T. Blaskovich, K.A. Hansford, Y. Gong, M.S. Butler, C. Muldoon, J.X. Huang, S. Ramu, A.B. Silva, M. Cheng, A.M. Kavanagh, Z. Ziora, R. Premraj, F. Lindahl, T.A. Bradford, J.C. Lee, T. Karoli, R. Pelingon, D.J. Edwards, M. Amado, A.G. Elliott, W. Phetsang, N.H. Daud, J.E. Deecke, H.E. Sidjabat, S. Ramaologa, J. Zuegg, J.R. Betley, A.P.G. Beevers, R.A.G. Smith, J.A. Roberts, D.L. Paterson, M.A. Cooper, Protein-inspired antibiotics active against vancomycin- and daptomycin-resistant bacteria, Nat. Commun. 9 (2018) 1-17. https://doi.org/10.1038/s41467-017-02123-w.

[29] N. Shibata, M. Ishida, Y. Venkata Rama Prasad, W. Gao, Y. Yoshikawa, K. Takada, Highly sensitive quantification of vancomycin in plasma samples using liquid chromatography-tandem mass spectrometry and oral bioavailability in rats, J. Chromatogr. B. 789 (2003) 211-218. https://doi.org/10.1016/S1570-0232(03)00068-0.

[30] S. Yamazaki, T. Suzuki, T. Suzuki, H. Takatsuka, M. Ishikawa, N. Hattori, T. Fujishiro, H. Miyauchi, T. Oami, N. Ariyoshi, S. Oda, H. Matsubara, I. Ishii, An extremely high bioavailability of orally administered vancomycin in a patient with severe colitis and renal insufficiency, J. Infect. Chemother. 23 (2017) 848-851. https://doi.org/10.1016/j.jiac.2017.08.004. 